\title{
A Preliminary Investigation of Velopharyngeal Timing in Normally Developing Preschool Children and Those with Speech Sound Disorders
}

Taylor Danielle Snodgrass

West Virginia University, tds0031@mix.wvu.edu

Follow this and additional works at: https://researchrepository.wvu.edu/etd

Part of the Speech and Hearing Science Commons

\section{Recommended Citation}

Snodgrass, Taylor Danielle, "A Preliminary Investigation of Velopharyngeal Timing in Normally Developing Preschool Children and Those with Speech Sound Disorders" (2019). Graduate Theses, Dissertations, and Problem Reports. 3801.

https://researchrepository.wvu.edu/etd/3801

This Thesis is protected by copyright and/or related rights. It has been brought to you by the The Research Repository @ WVU with permission from the rights-holder(s). You are free to use this Thesis in any way that is permitted by the copyright and related rights legislation that applies to your use. For other uses you must obtain permission from the rights-holder(s) directly, unless additional rights are indicated by a Creative Commons license in the record and/ or on the work itself. This Thesis has been accepted for inclusion in WVU Graduate Theses, Dissertations, and Problem Reports collection by an authorized administrator of The Research Repository @ WVU. For more information, please contact researchrepository@mail.wvu.edu. 
A Preliminary Investigation of Velopharyngeal Timing in Normally Developing

Preschool Children and Those with Speech Sound Disorders

\section{Taylor Snodgrass}

Thesis submitted to the College of Education and Human Services at West Virginia University in partial fulfillment of the requirements

for the degree of Master of Science in the Department of

Communication Sciences and Disorders

Dennis M. Ruscello, Ph.D., Chair

Kimberly Meigh. Ph.D.

Michelle Moore, Ph.D.

Department of Communication Sciences and Disorders

\section{Morgantown, West Virginia}

2019

Key Words: Speech motor control, speech delay, velopharyngeal timing 


\section{$\underline{\text { Abstract }}$ \\ A Preliminary Investigation of Velopharyngeal Timing in Normally Developing Preschool Children and Those with Speech Sound Disorders \\ Taylor Snodgrass}

As children acquire speech and language, they also begin to develop speech motor control. A widely accepted theoretical model for explaining speech acquisition and motor modifications necessary for appropriate speech is the Directions Into Velocities of Articulators (DIVA) model. This model posits that individuals plan and produce speech (feedforward system). If errors in speech are identified, they are modified since the DIVA Model includes a feedback system that is sensitive to such perturbations made during speech production (feedback system). This feedback system functions to make positive changes to one's motor programming for speech. Literature suggests that children gain stability of articulators as they mature, but children with speech sound disorders (SSDs) achieve stability of articulators, e.g. jaw and lips, at a later age than their typically developing peers which may suggest a breakdown in their feedforward system. However, to our knowledge, no previous studies have analyzed velopharyngeal timing differences in children with SSDs in comparison to their typically developing peers. There is some limited evidence that suggests children with language delays present with delays in velopharyngeal development, which caused the researchers of the study to question the possibility of velopharyngeal timing differences in children with SSDs of unknown etiology. The findings of the current study indicate more variability in velopharyngeal timing for children with SSDs; however, comparison with children who had typically developing speech did not always show statistically significant differences. The trend of variability in velopharyngeal timing that was identified should be further examined with larger subject groups. 


\section{Acknowledgements}

I would first like to thank my thesis advisor, Dr. Dennis Ruscello, for being such a wonderful mentor. He patiently explained expectations and concepts regarding my thesis and even went above and beyond by doing things like letting me go with him to the WVU Cleft Palate Clinic with him and helping me figure out future directions for clinical and research experience. Through this process, he has provided me with a plethora of information and guidance that challenged my ways of thinking and helped me grow as a researcher and clinician. I know I could not be where I am today without his encouragement and expertise along the way, and I am so grateful for his help.

I would also like to thank my thesis committee members, Dr. Michelle Moore and Dr. Kimberly Meigh, for their helpful feedback on this project. Their contributions helped me tremendously. They helped identify changes that needed to be made and weaknesses in the study which helped me grow as a researcher and writer. I sincerely appreciate the time spent providing me direction as committee members and professors. I would also like to thank Dr. Michelle Moore for taking the time to help me analyze the statistical data from this study and the guidance she provided through this process. 


\section{Table of Contents}

Chapter I: Review of Literature.........................................................1

- Speech Motor Control.................................................................1

- Theoretical Considerations............................................................3

- Speech Sound Disorders..............................................................4

- Velopharyngeal Closure for Speech................................................6

- Velopharyngeal Closure for Speech in Children with SSDs........................10

- Statement of the Problem...........................................................11

Chapter II: Methods.............................................................................14

$\quad$ Subjects..............................................................................14

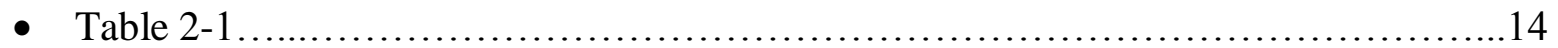

- Criterion Measures..........................................................................16

- Experimental Proced ure..........................................................19

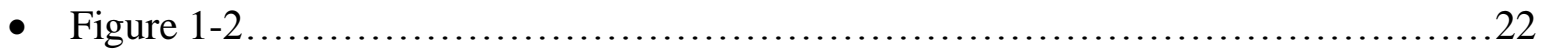

Chapter III: Results.........................................................................23

- Descriptive Analysis.............................................................23

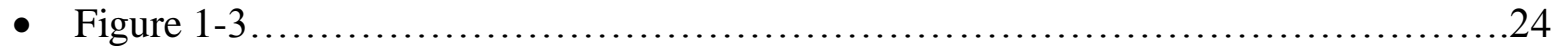

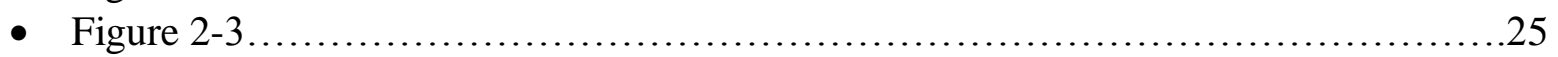

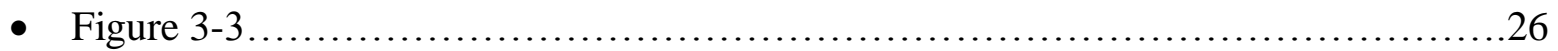

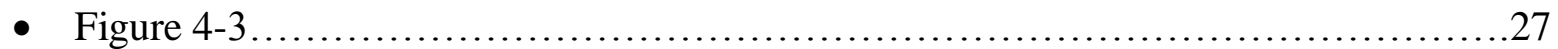

- Statistical Analysis...............................................................28

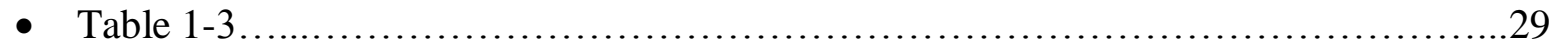

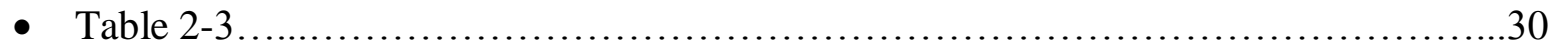

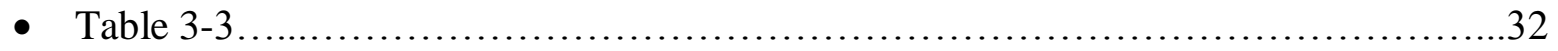

Chapter IV: Discussion.....................................................................34

$\quad$ Findings...........................................................................34

- Limitations...............................................................................36

- $\quad$ Future Directions......................................................................37

Appendix A: Consent Form.................................................................38

References........................................................................................41 


\section{Chapter I: Review of Literature}

\section{Speech Motor Control}

Speech motor control is composed of various systems and neuromuscular strategies which regulate speech production (Kent, 2000). This includes the formulation and preparation of speech movements and the actual translation of these movement plans into muscle contractions and displacement of various oral structures. Kent indicates that the input data in speech motor control consists of some type of phonologic representation of the language; specifically, a series of abstract phonemic units. The linguistic units are coded through a series of articulatory motor movements that create an acoustic signal that is interpreted by the intended listener.

The speech motor control system consists of the chest wall and respiratory mechanism, larynx, vocal tract, and articulatory components of the vocal tract that include the lips, teeth, tongue, jaw, and velopharynx (Barlow, Poore, \& Chu, 2011). These structures along with supporting muscles work in a synergistic relationship to facilitate the gradual development of speech motor control in children. During the developmental process, researchers have identified a level of variability in spatial and temporal goals that is greater than what is generally found in adult speech production (Green, Moore, \& Reilly, 2002; Nip, Green, \& Marx, 2009). Variability decreases with maturation of articulatory structures, and one of the first structures to achieve stability in speech production is the jaw. Movement of the mandible becomes stable in most children around one year of age (Green, Moore, \& Reilly, 2002). After a child has control of the mandible, they will then begin to exhibit more graded movements in upper and lower labial articulation (Green, Moore, \& Reilly, 2002; MacNeilage \& Davis, 1990a, 1990b). Mandibular support also facilitates the directional changes and quick movements of the tongue during speech (Phillips \& Kent, 1984). 
The study of speech articulation movement in children has been found to show more temporal fluctuation than the movements of adults, and one theoretical explanation for this suggests it is due to a lack of articulatory control (Green, Moore, \& Reilly, 2002). For example, Green, Moore, and Reilly (2002) studied infants' productions of the phrases "mama”, "baba”, and "papa" and compared them to adults producing the same phrases. The results of this study indicated that children's speech motor development was limited by their lack of articulatory control, and the authors suggested that the lack of control influences which sounds appear in a child's repertoire. They also found that speech motor control improved as children's articulatory systems matured.

Rvachew and Brosseau-Lapre (2018) cogently summarized the development of speech motor control in typically developing children across a number of different physiological and acoustic measurement parameters and reported similar trajectories of speech behavior. Children showed the early occurrence of adult-like coordinative infrastructure that was then followed by a period of experimentation in the spatial and temporal domains, which resulted in the eventual acquisition of speech sounds. For example, the initial stages of speech acquisition demonstrate active and involved experimentation of different vocal tract configurations. The end result of the experimentation is the synchronization of the different speech subsystems and the production of canonical syllables. The authors further indicate that despite the fact that overall coordinative infrastructure for speech is similar to the adult coordinative infrastructure, children's articulatory movements show greater displacements, extended durations, smaller velocities, and more variability than that found in the speech of young adults. It appears that the overall process is nonlinear and marked with various periods of exploration, in terms of change with age and rate of change for the various articulators and speech subsystems. However, the end result suggests 
articulatory control stabilizes with maturity. This study also suggests that articulatory temporal and spatial refinement continues beyond 16 years of age.

Research by Walsh and Smith (2002) also supports the position of early variability replaced by eventual stability of speech motor control. The researchers conducted a study with 120 subjects aged 12-22 to determine if there were changes in articulatory patterns during late adolescence, if sex had an impact on stability of articulators, and if the mandible would achieve stability prior to the upper and lower lips as reported in the literature of younger children. Data were collected by using a three-dimensional camera system that allowed them to study articulatory patterns during the production of the phrase "buy Bobby a puppy." The results of this study indicated that there was more variability of the articulators during adolescence than in young adulthood. It was suggested that this could be due to the fact that the oral cavity is growing due to rapid maturation during adolescence and then followed by subtle growth changes in young adulthood, which encourages articulatory stability (Steinburg, 1996). The results also indicated that sex has no influence on articulatory control. In addition, the authors reported that adolescent speech movements were longer in duration than that of young adults, and the movements patterns of adolescents were more variable than that of young adults. Furthermore, the study found that jaw movement was less variable than upper and lower labial movement; however, the results of the study suggested that even though jaw movement is less variable than that of the lips, the jaw does not achieve adult-like performance before the lips.

\section{Theoretical Considerations}

Perkell (2013) very eloquently stated that the theories and models of speech motor control over the years have allowed us to expand our knowledge base significantly. They serve as instruments for integrating research data into constructs that enable researchers to test rational 
and cogent hypotheses through experimental programs of study. Contemporary theories are based on acoustic, physiologic and/or perceptual rationales. The theories have become more complex and now integrate comprehensive information regarding anatomic structures and activation of those structures.

One of the most comprehensive models of speech motor control is that of Directions Into Velocities of Articulators (DIVA). This hypothetical model is derived from data and theoretical concepts in the literature based on the assumption that the primary aim of the motor control task is to transform underlying sequences of individual phonemic goals into groupings of quasicontinuous positional movements that create an intelligible acoustic signal. According to the DIVA model, phonemic goals consist of projections from premotor to sensory cortex, which convert sensory patterns that are expected to occur when articulating speech sounds (Perkell, 2013). DIVA consists of two primary subsystems, a feedforward control subsystem and a feedback control subsystem. Feedforward control is employed in the model for generating skillful, rapidly structured movements, and it functions separately of external (auditory, somatosensory) feedback. Feedback control involves external feedback and is utilized to teach, improve, and revise feedforward control mechanisms, based on error identification and subsequent modification.

\section{Speech Sound Disorders}

Research indicates that children with speech sound disorders demonstrate differences in speech motor control when compared with typically developing peers (Grigos, Hayden, \& Eigen, 2010; Grigos \& Kolenda, 2010; Grigos, Moss, \& Lu, 2015; Moss \& Grigos, 2012; Terband, Maassen, Van Lieshout, \& Nijland, 2011). For example, Case and Grigos (2016) found that children with speech sound disorders had more timing and jaw movement variability during 
speech than their typically developing peers. It should be noted that this could be due to the nature/classification of the speech sound disorder that was examined in the study, since the subjects in the investigation were reported to present with childhood apraxia of speech (CAS), which is characterized as a motor planning deficit.

When discussing speech sound disorders in general, it is to be noted that the classification is a generic term with subgroups that display different etiologies (Casper, 1985). For instance, causal factors may include structural malformations, hearing loss, and motor speech deficits (apraxia and dysarthria). However, the majority of speech sound disorders are a function of unknown etiologies or what is often labeled mislearning (Casper, 1985; Shriberg \& Kwiatkowski, 1994). These are children who display speech sound disorders but do not exhibit any significant causal agents to explain their speech sound disorder. The cause of their mislearning is attributed to issues with either encoding acoustic perceptions of phonological representations or storing these acoustic perceptions into memory (Shriberg, Lohmeier, Strand, \& Jakielski, 2012).

Despite differences in etiology, one factor that might be common among speech sound disorders in general is the delayed development of temporal control of different articulators. As mentioned previously, there has been previous research to analyze articulatory control in children with speech sound disorders, particularly those diagnosed with childhood apraxia of speech (Case \& Grigos, 2016).

For instance, Vick and associates (2014) administered a battery of tests including speech motor control tasks to a group of 97 preschool children. A total of 53 tasks, including kinematic, acoustic, and behavioral measures were employed and the data studied via a subgroup discovery algorithm. The authors identified subgroups of children who presented with speech motor 
control differences, but they cautioned that available standardized measures of speech would not be reliable in detecting differences in speech motor control among children with speech sound disorders. Measures sensitive to these differences generally require sophisticated instrumentation that is typically not available to practitioners. Nonetheless, subgroups with subtle speech motor control differences did emerge in the analysis of the data.

\section{Velopharyngeal Closure for Speech}

The velopharyngeal mechanism is an important articulator in speech production that has been studied infrequently. The velopharyngeal mechanism is composed of the velum, lateral pharyngeal walls, and the posterior pharyngeal wall. The space encompassed by these structures is referred to as the velopharyngeal port. There are five muscle pairs of the velum and pharynx that are involved in velopharyngeal movement: levator veli palatini, palatoglossus, musculus uvulus, palatopharyngeus, and tensor veli palatini. The velopharyngeal mechanism functions as an aerodynamic acoustic valve that creates a tight seal between the velum and posterior pharyngeal wall. It acts to separate the oral and nasal cavities (Zajac \& Vallino, 2017). At rest, when the mouth is closed and during nasal breathing, the velum may rest against the base of the tongue.

Velopharyngeal closure is a complex coordinated process that is necessary in order for speech to be produced correctly. It is dependent on the system's capacity to couple and decouple the nasal cavity from the oral cavity (Peterson-Falzone et al., 2010). In English, there are three nasal sounds /m, n, y/ that require oral-nasal coupling (i.e., an open velopharyngeal port), while the oral speech sounds require oral-nasal decoupling

(i.e. separation of the oral and nasal cavities). This process of coupling and decoupling the nasal and oral cavities is referred to as velopharyngeal valving, and it continuously adjusts to the 
phonetic demands of the sounds produced (Peterson-Falzone et al., 2010).

There are a limited number of studies that have been conducted to analyze velopharyngeal function in individuals without speech sound disorders. In some of these studies, velopharyngeal function is measured aerodynamically using the pressure-flow technique, which provides information on rates of nasal airflow, differential oral-nasal air pressure levels, and size estimates of the velopharyngeal opening (Warren \& DuBois, 1964). In addition, this method also allows the examiner to extract temporal data on specific aspects of velopharyngeal function by measuring air pressures and flows associated with specific phoneme sequences (Warren et al., 1985). For instance, in the word "hamper", the start of nasal flow during $/ \mathrm{m} /$ to the peak of oral pressure during /p/ can be interpreted as the time it took the individual to achieve velopharyngeal closure (Warren et al, 1993). The temporal characteristics used for measurement of velopharyngeal closure during the /mp/ sequence of the word "hamper" span multiple variables including the beginning of nasal airflow, the peak of nasal airflow, the beginning of oral pressure, the peak of oral pressure, and the end of oral pressure. These variables can be combined to evaluate different movement patterns of the velopharyngeal mechanism (Warren et al, 1993).

Zajac and Hackett (2002) used the pressure-flow technique to examine velopharyngeal function in 128 typically developing speakers: 46 of the participants were between 6-8 years of age, 41 were between 11-12 years of age, and 41 were between 18-37 years of age. In this study, six temporal parameters were measured while the word "hamper" was produced five times in continuous speech: beginning of nasal airflow-end nasal airflow, beginning of nasal airflow-peak of oral pressure, beginning of nasal airflow-end of oral pressure, peak nasal airflow-peak of oral pressure, beginning of oral pressure-peak of oral pressure, and the beginning of oral pressure-the 
end of oral pressure. Statistical analysis indicated significant main effects for chronological age on five of the six temporal measurement variables and for sex on three of the six timing measures. Statistical interactions between age of subject and sex were not found for any of the measures. The findings showed well-defined patterns of timing for the test stimuli produced by children and adults. Generally, adult subjects showed more temporal constancy when compared with the younger subject groups which suggests the velopharyngeal mechanism goes through a process of temporal development, similar to the previously discussed temporal development of the jaw and lips (Rvachew \& Brosseau, 2018; Walsh \& Smith, 2002; Green, Moore, \& Reilly, 2002). The durational delays and more speech segment variability found with the younger subjects suggest that variability be considered when engaging in the assessment and diagnosis of individuals with VPI.

Leeper et al. (1998) conducted a study that yielded similar results to that reported previously. In their study, the researchers used the pressure-flow technique to study 24 typically developing participants ages 3-12 using similar temporal measurement parameters. The authors reported that the aerodynamic protocol used to study velopharyngeal closure during the experimental tasks can reliably be employed with young children. The data indicated an inclination toward decreases in the duration of the timing measures as chronological age increased, which is consistent with previous findings on articulatory maturity in the jaw and lip (Rvachew \& Brosseau, 2018; Walsh \& Smith, 2002; Green, Moore, \& Reilly, 2002). Generally, the peak oral air pressure and nasal airflow findings were similar to the values found in other studies (Zajac \& Hackett, 2002; Zajac, 2000). These findings provide a model for studying the timing variables of velopharyngeal closure when conducting an aerodynamic evaluation with children who do not present with VPI (Zajac \& Hackett, 2002; Zajac, 2000; Leeper et al., 1998). 
Zajac (2000) conducted an additional study with normal speakers that consisted of children and adults. The pressure-flow technique was used to analyze the production of syllables /mi/, /pi/, and /pN/, the word "hamper", and the phrase "peep into the hamper". A total of 223 typically developing individuals participated in this study, and the subjects were divided into five groups based on age: ages 6-8 years old, ages 9-10 years old, ages 11-12 years old, ages 13-16 years old, and ages 18-37 years old. The researcher found that irrespective of age, approximately $95 \%$ to $99 \%$ of the subjects demonstrated complete VP closure during the production of /p/ at the syllable level. Statistical testing also revealed significant main effects of production level (word versus sentence) on each of the aerodynamic variables during the $/ \mathrm{mp} /$ sequence. The author noted that contextual differences were noted between word and sentence production with more instances of nasal airflow during single word productions when compared with sentence production.

Velopharyngeal function can also be measured using nasal ram pressure, which has been used to analyze velopharyngeal closure patterns of infants and toddlers (Bunton, Hoit, \& Gallagher, 2011). This is done by measuring nasal air pressure with a nasal cannula attached to the nares. This nasal cannula is connected to a pressure transducer. Ram pressure signals can be interpreted as positive pressure (the velopharynx is open while speaking on an inspiratory breath phrase), negative pressure (the velopharynx is open during speech on an expiratory breath phrase), and zero pressure (the velopharynx is closed during speech).

Thom, Hoit, Hixon, and Smith (2006) studied velopharyngeal closure patterns in a group of 6 infants. Nasal ram pressure was assessed monthly from age 2 months to age 6 months. The dependent variable measures consisted of distress and nondistress vocalizations produced by the infants. The authors found that two of the distress vocalizations (windups and whimpers) and 
one of nondistress vocalizations (laughs) were produced with an open velopharynx during each sampling period, but the velopharynx was closed when the subjects vocalized cries and screams (distress) and raspberries (nondistress). Velopharyngeal closure for speech-like utterances was found to increase with age but was not achieved completely by 6 months of age.

Bunton and Hoit (2018) recently conducted a longitudinal study with 92 children during their first two years of life (starting at about 4 months of age). The researchers used nasal ram pressure to determine at what age typically developing children achieve velopharyngeal closure during speech. This study is important because there is little literature that addresses the age at which velopharyngeal closure during speech occurs in children, and the current limited literature on this topic is equivocal. The results of this recent study indicated that the velopharyngeal mechanism achieves closure for at least $90 \%$ of oral utterances by 19 -months of age. Among subjects, the velopharynx was most commonly closed during the production of oral obstruents. This was followed by approximants, vowels, and glottal obstruents. However, it is important to note that there were variable closure patterns between subjects indicating inter-subject variability.

\section{Velopharyngeal Closure for Speech in Children with SSDs}

In a separate paper, Bunton (2018) discussed a subgroup of children with delayed language development that had been recruited for the Bunton and Hoit (2018) investigation. In their recruitment of potential subjects, a total of 5 subjects presented with "expressive language delay" (Bunton, 2018). Bunton noted that these subjects showed a lower number of measurable utterances, and more importantly, a delay in the onset of velopharyngeal closure for the utterances that were measured. For example, velopharyngeal closure was achieved on only $34 \%$ of the measured utterances at 4 months, while the typically developing children showed a closure 
rate of $60 \%$. At 21 months the delayed subjects demonstrated a closure rate of $81 \%$ when compared to a value of $96 \%$ at 19 months for the typically developing subjects. Although the subject pool was limited, the findings suggest that variability in speech motor control of the velopharynx may be also be a component that is found in children with expressive language delay.

Eshghi et al. (2017) conducted a longitudinal study using nasal ram pressure to examine velopharyngeal closure in a group of toddlers at three sampling periods that included 12,14 , and 18 months of age. There was a total of nine typically developing subjects and nine who presented with repaired cleft palate. Nasal ram pressure was measured during the production of oral stops and vowels in three different syllabic contexts. The typically developing children demonstrated velopharyngeal closure at 12 months of age and continued to exhibit the same pattern of closure at the subsequent measurement points. The cleft group showed significantly more instances of VPI at the first assessment but both groups did not differ at the 14 and 18month assessment periods.

\section{Statement of the Problem}

Theoretically, in order for individuals to produce meaningful speech, they must be able to conceptualize a semantic target, plan the speech movements associated with this target, and translate the plan into motor movements that result in intelligible speech (Kent, 2000; Shriberg et al., 2012). Articulatory control in terms of temporal and spatial variables are vital for achieving intelligible speech. Currently, there are normative data that provide some temporal and spatial information for children with typically developing speech and language. These data suggest that typically developing children achieve articulatory control through a gradual developmental process, which extends into adolescence. 
Considering this gradual developmental process, research suggests children with SSDs acquire articulatory control at a slower rate than their typically developing peers (Grigos, Hayden, \& Eigen, 2010; Grigos \& Kolenda, 2010; Grigos, Moss, \& Lu, 2015; Moss \& Grigos, 2012; Terband, Maassen, Van Lieshout, \& Nijland, 2011). However, the current literature on acquisition of articulatory control in children with SSDs has focused on labial and mandibular articulatory patterns and atypical groups, such as children with diagnosed apraxia of speech (CAS). Other important articulators, such as the velopharyngeal mechanism, have only recently been studied, and there is limited available empirical data on the performance of children with communication deficits and their trajectory to the achievement of perceptually "normal speech." The only existing study on this topic, to our knowledge, is the Bunton (2018) study on velopharyngeal timing in children with expressive language delay. Since there is indication that children with expressive language delays present with more variable velopharyngeal closure when compared with their typically developing peers, it raised the question regarding velopharyngeal timing patterns in children with SSDs of unknown etiology (Bunton, 2018).

The purpose of this study is to carry out a preliminary investigation of temporal variables related to velopharyngeal closure, using the pressure-flow technique, in a group of preschoolaged children with SSDs of unknown etiologies and judged "normal" resonance balance. Their performance will be compared to a group of subjects with typically developing speech who are in the same age range.

If children with SSDs of unknown etiology exhibit delays in speech motor control as assessed via the pressure/flow procedure, it indicates that delays encompass all of the articulators. That being said, treatment regimens for preschool children with SSDs of unknown etiology need to consider this variability when conducting treatment. This would include 
treatment variables such as the selection of stimuli, rate of stimuli presentation, rate of client responses, and determining appropriate response achievement criterion levels. 


\section{Chapter II: Methods}

\section{Subjects}

The subjects in this investigation consisted of preschool-aged children (ages 3-6) with speech sound disorders of unknown etiology and a cohort of children with typically developing speech and language. The children with speech sound disorders were recruited from children referred for diagnostic evaluations and/or treatment at the West Virginia University Speech and Hearing Center, and the children with typical speech development recruited from local preschool facilities, such as the West Virginia University Nursery School and parent contact.

For this preliminary study, we were able to identify three children with phonological disorders and six with typically developing speech. The small experimental sample size was due to a limited clinical population and resistance of the children to participate in the aerodynamic testing which will be further discussed later. In total, assessments were completed with three children with phonological disorders and six children with typically developing speech and language. The children in the study ranged in age from 3 years; 2 months to 5 years; 4 months. The mean age for the phonologically disordered group was 4 years; 5 months, while the mean age for the typically developing children was 4 years; 4 months. Please see Table $2-1$ for a complete summary of the assessment data used to identify the phonologically disordered and normal developing subjects.

\begin{tabular}{|c|c|c|c|c|c|c|}
\hline \multirow{4}{*}{ : } & \multicolumn{6}{|c|}{ Assessment Measures } \\
\hline & & DEAP & Fluharty-2 & OSME-3 & ICS & $\begin{array}{l}\text { Hearing } \\
\text { Screening }\end{array}$ \\
\hline & Subject 1 & $\begin{array}{l}\text { Age-appropriate } \\
\text { errors; presented } \\
\text { with gliding }\end{array}$ & $\begin{array}{l}\text { GLQ: } 90 \text {, } \\
\text { which is a } \\
\text { passing } \\
\text { score }\end{array}$ & $\begin{array}{l}\text { All } \\
\text { structures } \\
\text { were } \\
\text { WFL }\end{array}$ & $\begin{array}{l}\text { Total } \\
\text { score: } \\
28 ; \\
\text { average } \\
\text { score: } 4\end{array}$ & Passed \\
\hline & Subject 2 & $\begin{array}{l}\text { Age-appropriate } \\
\text { errors; presented }\end{array}$ & $\begin{array}{l}\text { GLQ: } 90 \text {, } \\
\text { which is a }\end{array}$ & $\begin{array}{l}\text { All } \\
\text { structures }\end{array}$ & $\begin{array}{l}\text { Total } \\
\text { score: }\end{array}$ & Passed \\
\hline
\end{tabular}




\begin{tabular}{|c|c|c|c|c|c|}
\hline & $\begin{array}{l}\text { with a couple } \\
\text { instances of } \\
\text { fronting }\end{array}$ & $\begin{array}{l}\text { passing } \\
\text { score }\end{array}$ & $\begin{array}{l}\text { were } \\
\text { WFL }\end{array}$ & $\begin{array}{l}28 ; \\
\text { average } \\
\text { score: } 4\end{array}$ & \\
\hline Subject 3 & $\begin{array}{l}\text { No delayed or } \\
\text { atypical speech } \\
\text { errors noted }\end{array}$ & $\begin{array}{l}\text { GLQ: 130, } \\
\text { which is a } \\
\text { passing } \\
\text { score }\end{array}$ & $\begin{array}{l}\text { All } \\
\text { structures } \\
\text { were } \\
\text { WFL }\end{array}$ & $\begin{array}{l}\text { Total } \\
\text { score: } \\
35 ; \\
\text { average } \\
\text { score: } 5\end{array}$ & Passed \\
\hline Subject 4 & $\begin{array}{l}\text { No delayed or } \\
\text { atypical speech } \\
\text { errors noted }\end{array}$ & $\begin{array}{l}\text { GLQ: } 105 \text {, } \\
\text { which is a } \\
\text { passing } \\
\text { score }\end{array}$ & $\begin{array}{l}\text { All } \\
\text { structures } \\
\text { were } \\
\text { WFL }\end{array}$ & $\begin{array}{l}\text { Total } \\
\text { score: } \\
35 ; \\
\text { average } \\
\text { score: } 5\end{array}$ & Passed \\
\hline Subject 5 & $\begin{array}{l}\text { No delayed or } \\
\text { atypical speech } \\
\text { errors noted }\end{array}$ & $\begin{array}{l}\text { GLQ: } 107 \text {, } \\
\text { which is a } \\
\text { passing } \\
\text { score }\end{array}$ & $\begin{array}{l}\text { All } \\
\text { structures } \\
\text { were } \\
\text { WFL }\end{array}$ & $\begin{array}{l}\text { Total } \\
\text { score: } \\
35 ; \\
\text { average } \\
\text { score: } 5\end{array}$ & Passed \\
\hline Subject 6 & $\begin{array}{l}\text { No delayed or } \\
\text { atypical speech } \\
\text { errors noted }\end{array}$ & $\begin{array}{l}\text { GLQ: } 107 \text {, } \\
\text { which is a } \\
\text { passing } \\
\text { score }\end{array}$ & $\begin{array}{l}\text { All } \\
\text { structures } \\
\text { were } \\
\text { WFL }\end{array}$ & $\begin{array}{l}\text { Total } \\
\text { score: } \\
35 ; \\
\text { average } \\
\text { score: } 5\end{array}$ & Passed \\
\hline Subject 7 & $\begin{array}{l}\text { Delayed/atypical; } \\
\text { presented with } \\
\text { final consonant } \\
\text { deletion and } \\
\text { glottal stopping }\end{array}$ & $\begin{array}{l}\text { GLQ: } 90 \text {, } \\
\text { which is a } \\
\text { passing } \\
\text { score }\end{array}$ & $\begin{array}{l}\text { All } \\
\text { structures } \\
\text { were } \\
\text { WFL }\end{array}$ & $\begin{array}{l}\text { Total } \\
\text { score: } \\
25 ; \\
\text { average } \\
\text { score: } \\
3.6\end{array}$ & Passed \\
\hline Subject 8 & $\begin{array}{l}\text { Delayed/atypical; } \\
\text { presented with } \\
\text { prevocalic } \\
\text { voicing, } \\
\text { labialization, } \\
\text { medial consonant } \\
\text { deletion, and } \\
\text { assimilation }\end{array}$ & $\begin{array}{l}\text { GLQ: } 95 \text {, } \\
\text { which is a } \\
\text { passing } \\
\text { score }\end{array}$ & $\begin{array}{l}\text { All } \\
\text { structures } \\
\text { were } \\
\text { WFL }\end{array}$ & $\begin{array}{l}\text { Total } \\
\text { score: } \\
26 ; \\
\text { average } \\
\text { score: } \\
3.7\end{array}$ & Passed \\
\hline Subject 9 & $\begin{array}{l}\text { Delayed/atypical; } \\
\text { presented with } \\
\text { vocalization of } \\
\text { liquids, } \\
\text { deaffrication, } \\
\text { cluster reduction, } \\
\text { fronting, weak } \\
\text { syllable deletion, } \\
\text { final consonant }\end{array}$ & $\begin{array}{l}\text { GLQ: 93, } \\
\text { which is a } \\
\text { passing } \\
\text { score }\end{array}$ & $\begin{array}{l}\text { All } \\
\text { structures } \\
\text { were } \\
\text { WFL }\end{array}$ & $\begin{array}{l}\text { Total } \\
\text { score: } \\
23 ; \\
\text { average } \\
\text { score: } \\
3.3\end{array}$ & Passed \\
\hline
\end{tabular}




\begin{tabular}{|l|l|l|l|l|l|}
\hline & $\begin{array}{l}\text { deletion, } \\
\text { assimilation, and } \\
\text { glottal stopping }\end{array}$ & & & & \\
\hline
\end{tabular}

Table 2-1. Results of the assessment battery required before completion of experimental procedure.

\section{Criterion Measures}

Articulation: All subjects were screened through administration of the Diagnostic Screen, which is a subtest of the The Diagnostic Evaluation of Articulation and Phonology (DEAP). The measure contains every American English consonant sound (Dodd, Hua, Crosbie, Holm, and Ozanne, 2006). The screening subtest consists of 10 pictures that are presented in combination with prompts by the examiner, and the stimuli vary in terms of complexity (there are some single syllable words, multisyllabic words and consonant clusters). The testing protocol consisted of three test conditions that included spontaneous presentation, followed by a stimulability test based on the child's errors. After the first two conditions were completed, the 10 pictures were shown a second time with the same prompts from the examiner to determine consistency of the child's speech errors. Each speech sound tested across the different stimulus conditions was scored as correct/incorrect by the examiner.

It should be noted that in order to conduct aerodynamic measures, the children had to have the speech sounds $/ \mathrm{p} /$ and $/ \mathrm{m} /$ in their speech sound inventory and be able to imitate the test token /hamper/. Children referred through the Allen Hall Speech and Hearing Center were considered "delayed or atypical", according to the DEAP, to qualify for the study. This indicated that the errors that the child made were not acceptable for their given age. Control subjects were considered "age appropriate", according to the DEAP. This indicated that they produced all appropriate speech sounds for their given age. All children in the experimental group had speech 
production skills that were deemed to be delayed according to the DEAP. Some examples of error patterns noted include prevocalic voicing, labialization, medial consonant deletion, assimilation, and glottal stopping. All children in the control group had speech production skills that were considered typical for their age, according to the DEAP. Some of the younger participants did present with phonological processes e.g. gliding or fronting; however, these processes are typical given their age. For more details on this, refer to Table 2-1.

In addition to the screening measure, the subject's caregiver completed the Intelligibility in Context Scale (ICS) (McLeod, Harrison, \& McCormack, 2012). This is a seven-item questionnaire that rates the subject's intelligibility along a 5-point scale that ranges from Always to Never. The intelligibility measure was administered to all subjects. The average total score for the experimental group, out of 35, was 24.7, and the average score for each question was 3.5. The controls had an average total score of 32.7 and the average score for each question was 4.7. For more details on this, refer to Table 2-1.

Language: Language was screened using the Fluharty Preschool Speech and Language Screening Test, Second Addition (Fluharty-2), which examines both receptive and expressive language skills (Fluharty, 2001). The General Language Quotient was calculated using the following subtests from the Fluharty-2: Repeating Sentences, Following Directions and Answering Questions, Describing Actions, and Sequencing Events. There are normative data to convert raw scores to standard scores and percentiles for each of the listed subtests, which can be summed to give the subject's General Language Quotient (GLQ). According to the Fluharty-2, a quotient score of 90 or above is "average", so all subjects participating in this study were required to have a quotient score of 90 or above. If not, they were deemed ineligible for the study. All participants passed the language screening. The average GLQ for the experimental 
group was 92.7, and the average GLQ for the control group was 104.8. For more details refer to Table 2-1.

Structural Observations: The examiner conducted an oral mechanism examination using the OSMSE-3: Oral Speech Mechanism Screening Examination-Third Edition for screening purposes (St. Louis \& Ruscello, 2000). The OSME-3 was utilized to evaluate the structure and function of the oral speech mechanism and insure that there were no structural, sensory, or motor variations that might adversely affect speech production skills. However, due to the age of the subjects and lack of normative data for preschool children, our main focus was to identify any structural variations that could interfere with speech production. Note that in most cases, significant motor or sensory problems would typically have been identified prior to this testing. Any subject who presented with a structural problem e.g. cleft lip and/or palate or midface hypoplasia was excluded from the study; however, all subjects passed the oral mechanism screening.

Resonance: The cul-de-sac testing procedure is a low-technology technique that was utilized to screen for resonance balance. The testing was as follows: The child was instructed to produce the high vowels /i/ or /u/ in a prolonged manner, while the examiner alternately opened and closed the nostrils with digital pressure. A change in resonance under the two conditions is indicative of hypernasal resonance and would result in ineligibility for participation in the study; however, hypernasality was not perceived during cul-de-sac testing with any of the participants.

Hearing Acuity: In addition to the speech screening measures, all subjects passed a hearing screening at $25 \mathrm{~dB}$ for the frequencies of $1000 \mathrm{~Hz}, 2000 \mathrm{~Hz}$, and $4000 \mathrm{~Hz}$. Hearing was screened with a Grason-Stadler GSI 17 portable audiometer, and all participants passed the screening. 
Criterion Measure Summary: All subjects were required to present with normal oral structure, resonance, expressive and receptive language skills, and hearing acuity to be eligible for the study. Speech sound production skills varied depending on age and group membership as specified previously. Prior to the conduct of the study, the researcher (TS) and thesis supervisor (DMR) reviewed the test materials and conducted practice examinations. In addition, the supervisor observed the testing for a majority of controls and experimental subjects. The researcher (TS) and supervisor (DMR) individually scored the tests for a single control subject and scores were compared. Interjudge point to point agreement for scoring the test items was $85 \%$.

\section{Experimental Procedure}

Aerodynamic testing: All subjects underwent aerodynamic testing to assess the temporal relationship of open versus closed velopharyngeal port. Each subject was fitted with an oral pressure tube and nasal olives to measure oral air pressure and nasal airflow. The physiologic parameter of oral pressure was measured by a pressure transducer and the results displayed on a computer monitor via the Perci SARS System 2.3. The nasal airflow was assessed with a Fleisch pneumotachograph and also displayed on the computer monitor. This instrumentation allowed the examiner to measure the oral and nasal aerodynamic parameters of interest. The equipment was calibrated before each subject was tested. Following the test manual, oral pressure was calibrated using a water manometer and airflow was calibrated using an air source and rotameter.

The testing stimuli consisted of the bilabial plosive $/ \mathrm{p} /$ and nasal $/ \mathrm{m} /$ since they permit placement of the oral sensing tube without discomfort and demonstrate conditions of the velopharyngeal port open and closed. Temporal relationships involved in velopharyngeal closure were measured during productions of the word hamper, since the experimental token 
requires production of the speech sound $/ \mathrm{m} /$ (open velopharyngeal port) and then transition to the speech sound /p/ (closed velopharyngeal port).

Each subject was instructed to repeat the word token five times prior to testing at a normal rate of speech and vocal intensity for practice purposes. Subjects were then fitted with a nasal airflow sensor via nasal olives inserted at the openings of the nares, and an oral pressure sensing tube that was inserted behind the lips perpendicular to oral airflow. The timing acquisition period was set to sample for 10 seconds. After this, they repeated the token again five times without measurement to familiarize the subjects with the equipment in place and the speech production requirements. This served as the second and last practice period. Following practice, each subject was instructed to repeat the test token five times (each time immediately following a prompt from the experimenter) over three trials with the system in measurement mode. However, in some cases, the children were hesitant to repeat the stimuli and less than 5 tokens were obtained in a 10 second sampling mode. Conversely, some of the subjects actually produced more than 5 tokens during a sampling period. The experimenter tried to control for rate by having each subject repeat "hamper" immediately following a prompt. Subjects were given a short break between each block of five repetitions. In all, a total of at least 15 token repetitions per subject were obtained. The number of repetitions across subjects ranged from 15 to 35 , and the average number of repetitions was 22 .

Measurement: Figure 1-2 is taken from Zajac and Hackett (2002) and shows the measurement parameters that were used to measure the aerodynamic parameters. There were six measurement points that were used to quantify the temporal relationships of interest and they included: (1) Duration of nasal airflow (1-3), (2) Start of nasal airflow to peak oral pressure for /p/ (1-5), (3) Start of nasal airflow to cessation of oral pressure for /p/ (1-6), (4) Maximum nasal 
airflow during /m/ to maximum oral pressure for /p/ (2-5), (5) Initiation of oral pressure to maximum oral pressure for $/ \mathrm{p} /(4-5)$, and (6) initiation of oral pressure to cessation of oral pressure for $/ \mathrm{p} /(4-6)$.

Reliability: Measurement of intra and inter judge reliability was carried out through the computation of intraclass correlations (George \& Mallery, 1999). The statistic (ICC) is used in cases where reliability estimates are needed to compare observations within and between judges. TS randomly selected a subject from each of the two groups and re-measured the temporal parameters for 90 measurements; there were 45 measurements for each subject. An ICC was computed and found to be $.996(\mathrm{p} \leq .001)$. Interjudge reliability was determined through the measurement of 60 temporal measurements that were randomly selected from a subject in each group and measured independently by TS and DMR. There were 30 measurements for each subject. Computation of ICC was carried out and the resulting correlation was .896 ( $\mathrm{p} \leq .001)$. 

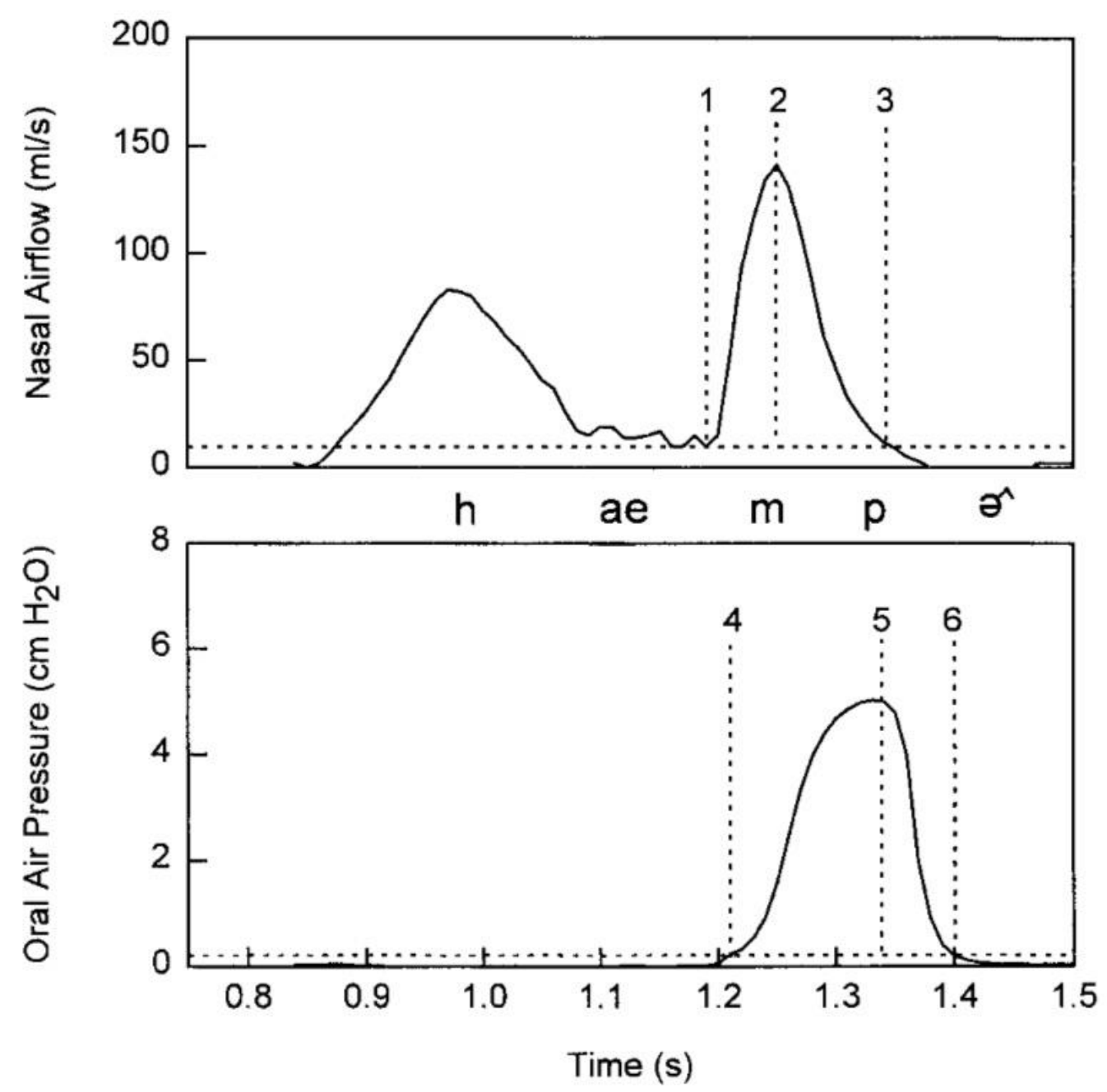

Figure 1-2. This figure was taken from Zajac and Hackett (2002) and shows the different measurement parameter points that are used to examine the temporal relationships of velopharyngeal motor control. 


\section{Chapter III: Results}

\section{Descriptive Analysis}

Data for the 6 temporal measurement parameters discussed previously were collected for all subjects in both the experimental and control groups. Please refer to Figure 1-2 for a summary description of the parameters. Initially, all graphs were inspected visually to identify any trends in the data with respect to group membership and chronological age. There was observed variability in both nasal air flow and oral pressure durations which will be discussed.

As a frame of reference, an example of an aerodynamic tracing for a typically developing preschool-aged child is displayed Figure 1-3. The tracing was obtained from a child aged 4 years; 4 months. Note that the nasal airflow during production of the $/ \mathrm{m} / \mathrm{in}$ "hamper" is seen on the top half of the graph (See top arrow), and the oral pressure during production of the /p/ in "hamper" is seen on the bottom half of the graph (See bottom arrow). The arrows isolate one repetition of the stimulus word hamper. Further perusal of Figure 1-3 shows some individual variability with this participant, as with most of the other children in the study. The nasal airflow duration was relatively short with reduced nasal airflow and ended around the time of peak oral pressure with some variability toward the end of the sample. Oral pressure values also show variability in terms of duration and magnitude. 


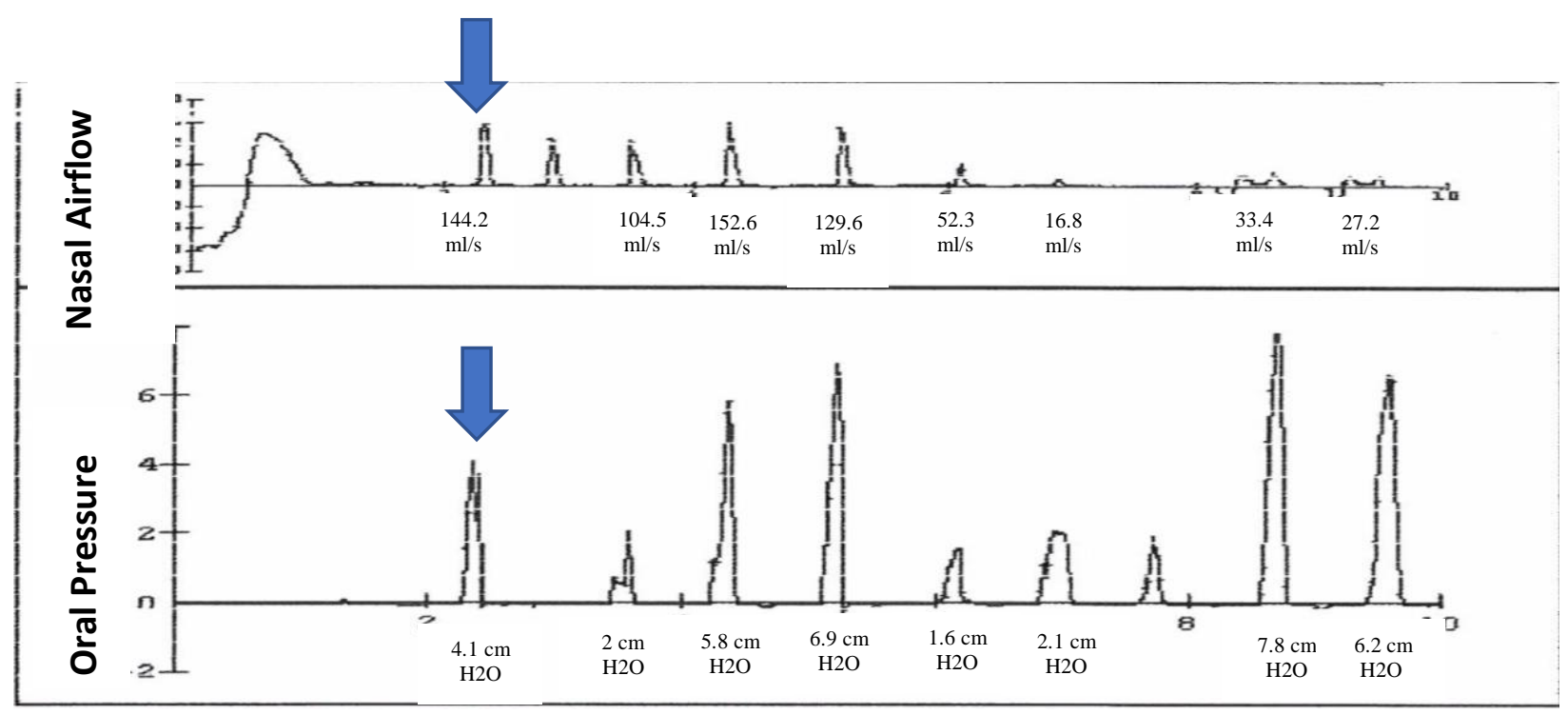

Figure 1-3. This tracing was taken during the study and represents pressure-flow measurements via the Perci SARS System 2.3 of a typical developing preschool-aged child who is 4 years; 4 months of age.

The first trend that was found across groups appeared to be related to chronological age. That is, regardless of group membership, younger subjects tended to have longer nasal airflow durations. Please refer to Figure 2-3 for an example of this. This figure was taken from the trials of a typically developing child aged 3 years; 2 months. In Figure 2-3, the arrow on the top half of the graph represents nasal airflow during one production of $/ \mathrm{m} /$ in hamper, and the bottom half of the graph represents one oral pressure peak of $/ \mathrm{p} /$ during the production of hamper. Nasal airflow peaks but duration is extended with a duration of 1.3 seconds in this example. This indicates that the velopharyngeal port was open for a longer duration when compared to the typically developing child who was 4 years; 4 months (whose nasal airflow duration during the first production of hamper in Figure 1-3 was $147 \mathrm{msec}$ ). It is important to note that even though there are longer nasal airflow durations with typically developing children who are younger, the duration of their oral air pressure did not vary substantially. 


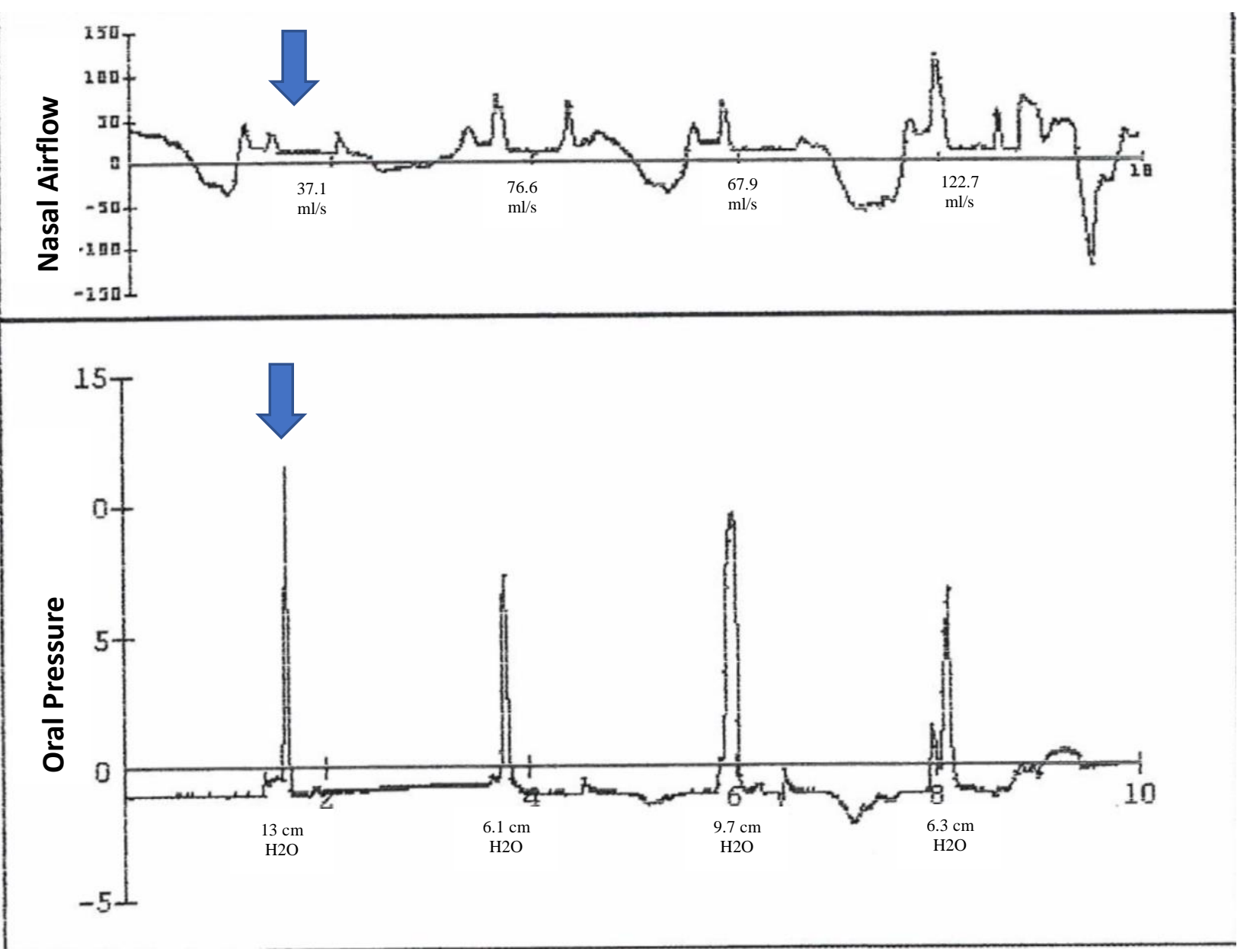

Figure 2-3. This figure is a tracing taken from a typically developing preschool-aged child who is $3 ; 2$.

Another trend noted was that participants in the experimental group presented with nasal airflow continuation on some trials, even after oral pressure from $/ \mathrm{p} /$ had ended. For instance, please refer to Figure 3-3. The arrows on the top half of the graph indicate examples of the longer duration of nasal airflow, and the arrows on the bottom half of the graph indicate the length of oral pressure. Nasal airflow continues after oral pressure ends, and this pattern is seen in 4 out of the 6 productions of "hamper" as shown in the figure (all of which are designated with arrows). This pattern was only noted with one participant in the control group, whose 
chronological age was 3 years; 2 months. As previously noted, the duration of nasal airflow was longer in younger children regardless of group membership.

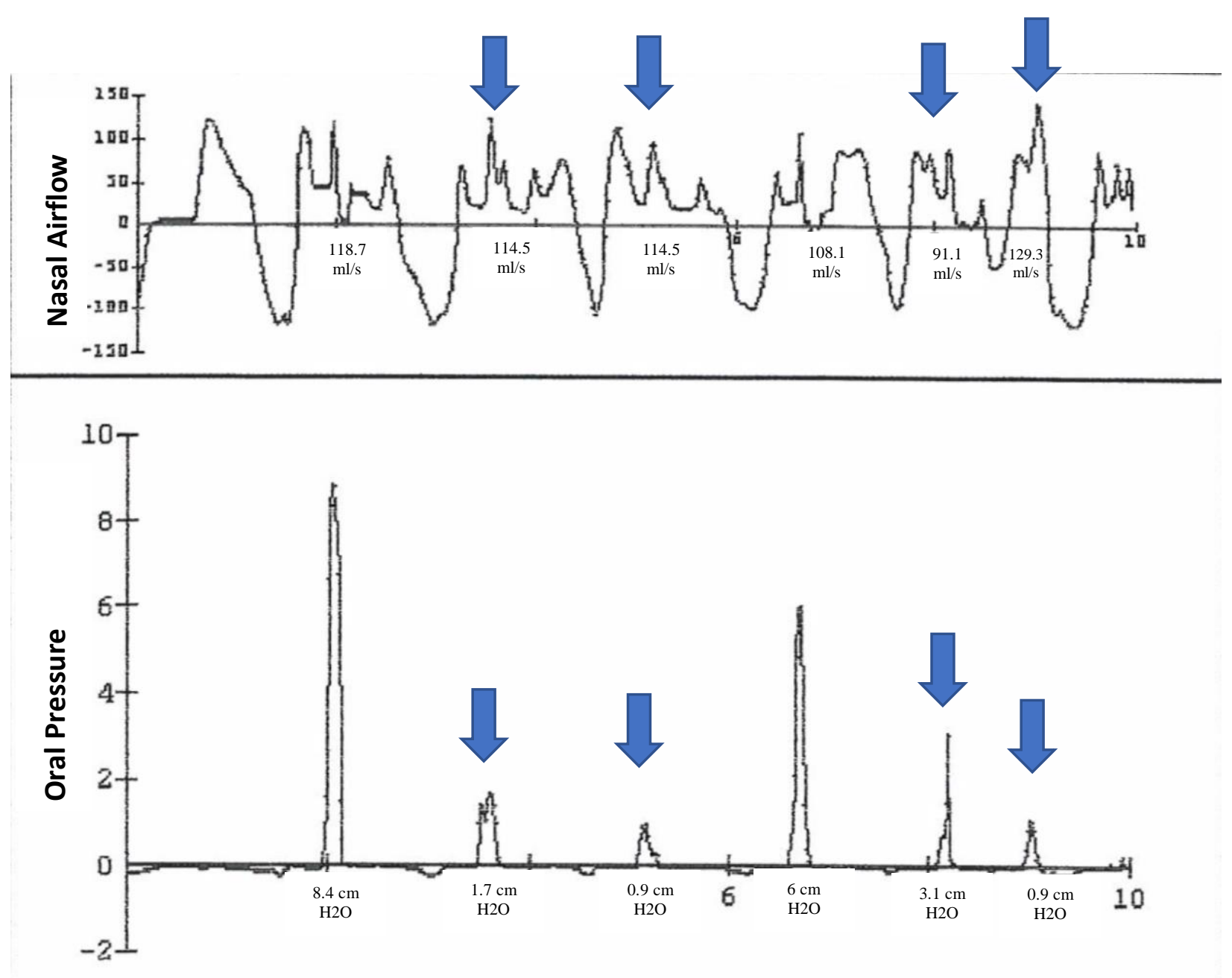

Figure 3-3. This tracing was from a taken a preschool-aged child with a speech sound disorder of unknown etiology whose age is 3 years; 11 months.

The final instance of variable performance noted was that 2 of the 3 participants in the experimental group had longer oral pressure durations than what was found with the other participants. An example of this is shown in Figure 4-3. The arrows on the bottom half of the graph show oral pressure durations during multiple productions of hamper. There is a longer duration of oral pressure as depicted in the figure. 


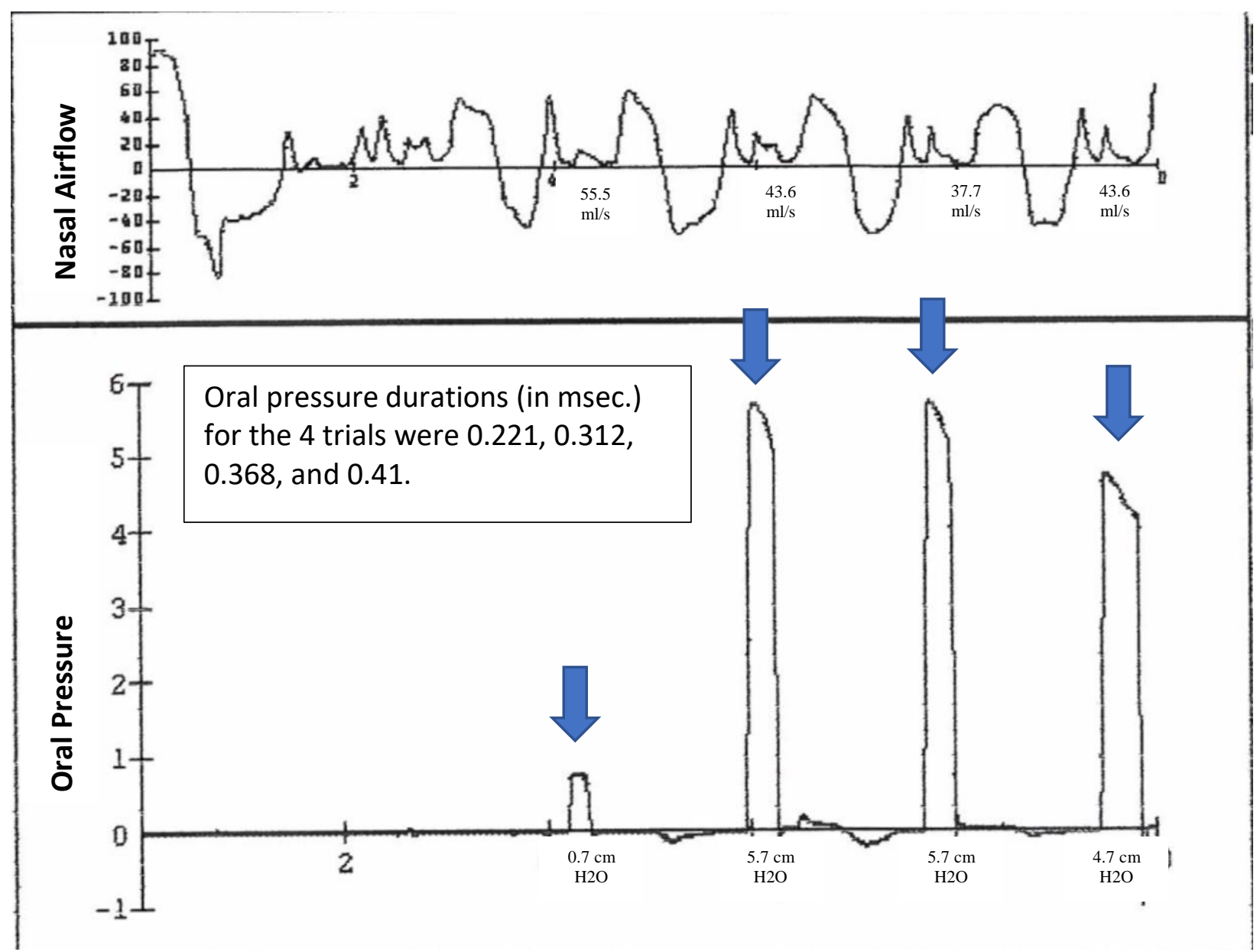

Figure 4-3. This tracing was collected from a preschool-aged child with a speech sound disorder of unknown etiology whose age is 5 years; 6 months.

In sum, visual analysis of the data indicated variability across sampling trials for groups (experimental versus control) and subjects (younger subjects versus older subjects). This variability is attributed to children's development of speech motor control. That is, variability was identified as both a function of study group and chronological age, which would be consistent with reports in the literature that have reported developmental differences as children develop speech motor control (Grigos, Hayden, \& Eigen, 2010; Grigos \& Kolenda, 2010; Grigos, Moss, \& Lu, 2015; Moss \& Grigos, 2012; Terband, Maassen, Van Lieshout, \& Nijland, 2011). 


\section{Statistical Analysis}

Statistical analyses were conducted for each of the 6 temporal measures through the computation of individual t-tests in order to determine if there were statistically significant differences between groups. The SPSS statistical package (George \& Mallery, 1999) was used for computation purposes. Since multiple independent t-tests were being computed based on the average temporal data for each subject from the 6 segments previously mentioned, the Bonferroni correction was applied (Weisstein, 2004). This statistic adjusts probability values when a number of dependent or independent statistical tests are being used with a single data set. Table 1-3 shows the results of the statistical testing. The mean score values for the experimental group are consistently greater than those of the control group indicating longer durations in the parameters measured. However, while some of the measurement variables approached rejection of the null hypothesis, none reached the corrected level of statistical significance for a one-tailed test $(\mathrm{p} \leq .004)$.

Since data differences were identified between groups, the Cohen's d statistic (Cohen, 1977) was computed for each of the measurement variables. This statistic is generally computed to estimate the degree of difference between two or possibly additional groups on a specific variable. With this statistic, larger values indicate a greater difference between groups on the variable being measured. Cohen estimates values of 0.20 to 0.49 indicate a small effect size, 0.50 to 0.79 suggest a moderate effect size, and 0.80 or greater suggests a large effect size (Cohen, 1988). A moderate effect size or greater was found for temporal data segments 1 (duration of nasal airflow, 1.11), 3 (start of nasal airflow to end of oral pressure, .92), 4 (peak of nasal airflow to peak of oral pressure, .75), 5 (start of oral pressure to peak of oral pressure, 1.41), and 6 (start of oral pressure to end of oral pressure, 2.67). The results are summarized in Table 1-3. 


\begin{tabular}{|c|c|c|c|c|c|}
\hline $\begin{array}{c}\text { Temporal } \\
\text { Data }\end{array}$ & $\begin{array}{c}\text { Control } \\
\text { Group (n=6): } \\
\text { Mean } \\
\text { (Standard } \\
\text { Deviation) }\end{array}$ & $\begin{array}{c}\text { Experimental } \\
\text { Group (n=3): } \\
\text { Mean } \\
\text { (Standard } \\
\text { Deviation) }\end{array}$ & T & p & Cohen's d \\
\hline $\begin{array}{c}\mathbf{1} \text { (duration of } \\
\text { nasal airflow) }\end{array}$ & $\begin{array}{c}0.498814 \\
(0.199830)\end{array}$ & $\begin{array}{c}0.665245 \\
(0.046184)\end{array}$ & -1.379 & 0.12 & 1.11 \\
\hline $\begin{array}{c}\mathbf{2} \text { (start of } \\
\text { nasal airflow } \\
\text { to peak of oral } \\
\text { pressure) }\end{array}$ & $\begin{array}{c}0.4665 \\
(0.149653)\end{array}$ & $\begin{array}{c}0.495198 \\
(0.013970)\end{array}$ & -0.320 & 0.758 & 0.26 \\
\hline $\begin{array}{c}\mathbf{3} \text { (start of } \\
\text { nasal airflow } \\
\text { to end of oral } \\
\text { pressure) }\end{array}$ & $\begin{array}{c}0.54187 \\
\mathbf{4} \text { (peak of }\end{array}$ & $\begin{array}{c}0.134812) \\
(0.084271)\end{array}$ & -1.144 & 0.290 & 0.92 \\
$\begin{array}{c}\text { nasal airflow } \\
\text { to peak of oral } \\
\text { pressure) }\end{array}$ & $(0.0689)$ & $(0.091762)$ & -0.931 & 0.383 & 0.75 \\
\hline $\begin{array}{c}\mathbf{5} \text { (start of oral } \\
\text { pressure to } \\
\text { peak of oral } \\
\text { pressure) }\end{array}$ & 0.108866 & 0.149217 & -1.763 & 0.121 & 1.41 \\
\hline $\begin{array}{c}\mathbf{6} \text { (start of oral } \\
\text { pressure to } \\
\text { end of oral } \\
\text { pressure) }\end{array}$ & $\begin{array}{c}(0.028828) \\
(0.054435)\end{array}$ & $\begin{array}{c}(0.039843) \\
(0.049672)\end{array}$ & & & \\
\hline
\end{tabular}

Table 1-3. Results of the comparison between groups for the six measurement variables.

Following the initial analysis, additional statistical testing was done to examine further the data set with respect to differences between groups. It was noted that two of the children in the control group were 11 months younger than all other participants in the study and could have skewed the results, since it was noted that younger children tended to have longer overall durations than older children (refer to Figure 1-3). Because of this, an additional statistical analysis was carried out with the computation of multiple independent t-tests based on the average of the 6 segments previously mentioned for each participant, which excluded the 
performance data from the two youngest children in the study who happened to be in the control group (both 3 years; 2 months). The corrected level of statistical significance remained the same at $\mathrm{p} \leq 0.004$. While none of the dependent variable measures were found to be statistically significant, two of them were trending: 1 (duration of nasal airflow), $\mathrm{p}=0.026$ and 6 (start of oral pressure to end of oral pressure), $\mathrm{p}=0.036$. This indicates the children with SSDs presented with longer nasal airflow and oral pressure durations during the $/ \mathrm{mp} /$ sequence of hamper. Using Cohen's d, large effect size was suggested for temporal data segments 1 (duration of nasal airflow, 2.82), 3 (start of nasal airflow to peak of oral pressure, .94), 4 (peak of nasal airflow to peak of oral pressure, 1.07), 5 (start of oral pressure to peak of oral pressure, 1.46), and 6 (start of oral pressure to end of oral pressure, 2.58). The results from the analysis are presented in Table 2-3.

\begin{tabular}{|c|c|c|c|c|c|}
\hline $\begin{array}{l}\text { Temporal } \\
\text { Data }\end{array}$ & $\begin{array}{c}\text { Control } \\
\text { Group }(n=4): \\
\text { Mean } \\
\text { (Standard } \\
\text { Deviation) } \\
\end{array}$ & $\begin{array}{c}\text { Experimental } \\
\text { Group }(n=3): \\
\text { Mean } \\
\text { (Standard } \\
\text { Deviation) } \\
\end{array}$ & $\mathbf{T}$ & $\mathbf{p}$ & Cohen's d \\
\hline $\begin{array}{l}\mathbf{1} \text { (duration of } \\
\text { nasal airflow) }\end{array}$ & $\begin{array}{c}0.405076 \\
(0.136715) \\
\end{array}$ & $\begin{array}{c}0.665245 \\
(0.046184) \\
\end{array}$ & -3.122 & 0.026 & 2.82 \\
\hline $\begin{array}{c}2 \text { (start of } \\
\text { nasal airflow } \\
\text { to peak of oral } \\
\text { pressure) }\end{array}$ & $\begin{array}{c}0.442195 \\
(0.186831)\end{array}$ & $\begin{array}{c}0.495198 \\
(0.013970)\end{array}$ & -0.479 & 0.652 & 0.43 \\
\hline $\begin{array}{c}3 \text { (start of } \\
\text { nasal airflow } \\
\text { to end of oral } \\
\text { pressure) }\end{array}$ & $\begin{array}{c}0.527321 \\
(0.171096)\end{array}$ & $\begin{array}{c}0.640985 \\
(0.084271)\end{array}$ & -1.042 & 0.345 & 0.94 \\
\hline $\begin{array}{l}4 \text { (peak of } \\
\text { nasal airflow } \\
\text { to peak of oral } \\
\text { pressure) }\end{array}$ & $\begin{array}{c}0.137726 \\
(0.071818)\end{array}$ & $\begin{array}{c}0.201238 \\
(0.091762)\end{array}$ & -1.034 & 0.348 & 1.07 \\
\hline $\begin{array}{c}5 \text { (start of oral } \\
\text { pressure to } \\
\text { peak of oral } \\
\text { pressure) }\end{array}$ & $\begin{array}{c}0.114290 \\
(0.016683)\end{array}$ & $\begin{array}{c}0.149217 \\
(0.039843)\end{array}$ & -1.615 & 0.167 & 1.46 \\
\hline
\end{tabular}




\begin{tabular}{|c|c|c|c|c|c|}
\hline $\mathbf{6}$ (start of oral & 0.202092 & 0.310289 & -2.851 & 0.036 & 2.58 \\
$\begin{array}{c}\text { pressure to } \\
\text { end of oral } \\
\text { pressure) }\end{array}$ & $(0.049691)$ & $(0.049672)$ & & & \\
\hline
\end{tabular}

Table 2-3. Results of the comparison between groups for the six measurement variables with the two youngest controls excluded from the analysis.

Initially, the researchers planned to enroll 20 participants: 10 in the control group and 10 in the experimental group. The rationale was to employ a matched pairs design that would match based on age and sex, but this selection strategy was not feasible and will be discussed later. However, the experimenters identified 2 sets of subjects that could be paired by age and sex for further examination. There were two boys in the study (one in the experimental group and one in the control) who were the same age (within 6 days); the younger child in the pair was in the control group. There were also two girls in the study (one in the experimental group and one in the control) who were the same age (within 4 months); the younger child in the pair was in the control group. A statistical analysis, using multiple independent t-tests, was conducted to compare differences between the two groups and is presented in Table 3-3. The corrected level of statistical significance remained the same at $\mathrm{p} \leq 0.004$. It should be noted that, because there were so few participants included in this particular analysis, individual trials were used to compute the t-tests as opposed to the average of the 6 segments which was used in the other two statistical analyses. Statistically significant differences were found for 1 (duration of nasal airflow), $\mathrm{p}=0.003,5$ (start of oral pressure to peak of oral pressure), $\mathrm{p}=0.000$, and 6 (start of oral pressure to end of oral pressure), $\mathrm{p}=0.000$. Cohen's $\mathrm{d}$ indicated a moderate effect size or greater for temporal data segments $1(0.71), 5(0.98)$, and $6(0.94)$. The results from the analysis are presented in Table 3-3. 


\begin{tabular}{|c|c|c|c|c|c|}
\hline $\begin{array}{c}\text { Temporal } \\
\text { Data }\end{array}$ & $\begin{array}{c}\text { Control } \\
\text { Group } \\
(\mathbf{n = 3 2}) \text { : } \\
\text { Mean } \\
\text { (Standard } \\
\text { Deviation) }\end{array}$ & $\begin{array}{c}\text { Experimental } \\
\text { Group }(n=48) \text { : } \\
\text { Mean } \\
\text { (Standard } \\
\text { Deviation) }\end{array}$ & $\mathbf{T}$ & $\mathbf{p}$ & Cohen's d \\
\hline $\begin{array}{l}\mathbf{1} \text { (duration of } \\
\text { nasal airflow) }\end{array}$ & $\begin{array}{c}0.47031 \\
(0.322264)\end{array}$ & $\begin{array}{c}0.69102 \\
(0.310868)\end{array}$ & -3.066 & $0.003 *$ & 0.71 \\
\hline $\begin{array}{c}\mathbf{2} \text { (start of } \\
\text { nasal airflow } \\
\text { to peak of oral } \\
\text { pressure) }\end{array}$ & $\begin{array}{c}0.54813 \\
(0.399841)\end{array}$ & $\begin{array}{c}0.48813 \\
(0.212331)\end{array}$ & 0.873 & 0.385 & 0.20 \\
\hline $\begin{array}{c}3 \text { (start of } \\
\text { nasal airflow } \\
\text { to end of oral } \\
\text { pressure) }\end{array}$ & $\begin{array}{c}0.63137 \\
(0.392743)\end{array}$ & $\begin{array}{c}0.59694 \\
(0.235026)\end{array}$ & 0.491 & 0.625 & 0.11 \\
\hline $\begin{array}{c}4 \text { (peak of } \\
\text { nasal airflow } \\
\text { to peak of oral } \\
\text { pressure) }\end{array}$ & $\begin{array}{c}0.11644 \\
(0.149219)\end{array}$ & $\begin{array}{c}0.14750 \\
(0.125338)\end{array}$ & -1.006 & 0.318 & 0.23 \\
\hline $\begin{array}{l}5 \text { (start of oral } \\
\text { pressure to } \\
\text { peak of oral } \\
\text { pressure) }\end{array}$ & $\begin{array}{c}0.09981 \\
(0.027828)\end{array}$ & $\begin{array}{c}0.15794 \\
(0.074203)\end{array}$ & -4.230 & $0.000 *$ & 0.98 \\
\hline $\begin{array}{c}6 \text { (start of oral } \\
\text { pressure to } \\
\text { end of oral } \\
\text { pressure) }\end{array}$ & $\begin{array}{c}0.16331 \\
(0.051438)\end{array}$ & $\begin{array}{c}0.28917 \\
(0.169256)\end{array}$ & -4.075 & $0.000 *$ & 0.94 \\
\hline
\end{tabular}

Table 3-3. Results of the comparison between groups for the six measurement variables that included only the two matched pairs.

Both the descriptive and inferential analyses indicated differences between groups and chronological age, which appear to reflect maturation of the velopharyngeal mechanism for speech. It would appear that during the preschool period, speakers have significant degrees of freedom when speaking in contexts that involve opening and closing of the velopharyngeal mechanism. They are working toward consistency but there were differences found in both nasal airflow and oral pressure that would imply they need to continue to practice speech as would be 
expected. In addition, although the experimental group was limited in number, the analysis of performance data revealed trends that indicate more variability in velopharyngeal control for children who present with SSDs. 


\section{Chapter IV: Discussion}

\section{Findings of the Study}

This study suggests, that like other articulators such as the jaw and lips, the velopharyngeal mechanism gradually achieves stability over time. In this investigation, temporal variables were examined to obtain data on the operation of the velopharyngeal mechanism in preschool children with and without speech disorders. Our findings are limited as a function of sample size, but statistical analysis did show a number of trends per different comparisons of the two groups. Our preliminary findings indicate that variability in the operation of the velopharyngeal mechanism is present in the speech of preschool children. Moreover, the variability appears greater in children with SSDs than their typically developing peers, and our findings are in agreement with other investigators who have studied different speech motor control variables in younger children (Grigos, Hayden, \& Eigen, 2010; Grigos \& Kolenda, 2010; Grigos, Moss, \& Lu, 2015; Moss \& Grigos, 2012; Terband, Maassen, Van Lieshout, \& Nijland, 2011).

Our reported findings support Zajac \& Hackett's (2002) previous research that there is more temporal variability in the velopharyngeal activity of younger children. As previously discussed, the younger children in this investigation presented with more temporal variability in terms of longer durational measures, regardless of group membership. This suggests continued development and refinement of speech motor control for the velopharynx when speakers must adjust for the opening and closing of the velopharyngeal port and produce intelligible speech. This is similar to Case and Grigo's (2016) findings which suggested that children with apraxia of speech had more jaw variability than their typically developing peers. It is interesting to note that during the aerodynamic assessments, the researchers did not perceive hypernasality, even 
though variability in velopharyngeal opening and closing was noted across the performance of a majority of the subjects.

Our findings also identified trends to suggest slower and more variable velopharyngeal timing in children with SSDs. One of the few studies related to the current study was conducted by Bunton (2018) and suggested that young children with language deficits also presented with differences in velopharyngeal valving. The researchers in this investigation feel that Bunton's work and the current findings have clinical relevance for SLPs who provide services to preschool children in early intervention and other preschool treatment settings. When examining a child or making treatment recommendations, the clinician may want to make accommodations e.g. the clinician might want to present stimuli for phonological treatment at a consistent rate in consideration of the velopharyngeal timing differences. In addition, some SLPs use drill practice paradigms that have the child repeat a word or phrase in rote fashion and with a rapid rate. This is a practice that would not be recommended as the child should be given time to produce a stimulus item and receive appropriate intrinsic and extrinsic feedback. It might be more efficient to elicit fewer responses than attempting to increase rate and obtain more practice repetitions (Ruscello \& Vallino, 2014).

Continued research is necessary to provide additional confirmation of the current findings and support the clinical implications discussed. In addition, future studies with other populations of children with SSDs, such as children with structural defects e.g. cleft palate, may also be beneficial. Children born with palatal clefts undergo surgery at a young age and some children achieve closure, while others do not and require secondary surgical procedures at an older age (Zajac \& Napoli-Vallino, 2017). The children in the latter group may benefit from assessment that includes studies of velopharyngeal timing, rather than our current assessment paradigm that 
uses multiple physiologic measures but does not specifically study temporal movement variables of the velopharyngeal mechanism (Zajac \& Napoli-Vallino, 2017). Further study of temporal variables may lead to study methods that identify factors leading to improved surgical correction of children who present with velopharyngeal dysfunction.

\section{Limitations}

The major limitation of this investigation was the inability to recruit the desired number of subjects. Originally, the idea was to recruit 20 subjects; 10 for the experimental group and 10 for the control group. It would have been more empirically grounded to statistically compare the two groups with a larger sample size that would afford a more representative study of velopharyngeal timing in children with SSDs in comparison to their typically developing peers. It is likely that the trends that were present in the data would have reached some level of statistical significance with the original projected number in each of the two study groups given the visual patterning and statistical trending of the data.

It is important to note that the manner in which the researchers analyzed data could have also played a role in the findings of statistical significance. As previously mentioned, in the first two analyses, the researchers took the average timing data from the 6 segments for each child; therefore, $n=3$ for the experimental group and $n=6$ for the control group. With the last analysis conducted, the researchers based it on individual trials for each participant (an average was not formulated); therefore $n=48$ for the experimental group and $n=32$ for the control group. Findings of statistical significance could, in part, be impacted by the manner in which the data were entered in the analyses.

It is also worth noting that many children in this study were hesitant to participate in the 
experimental procedure. This impacted recruitment and also required the researchers to carry out experimental procedure with some children at a later date, separate from the screenings because they were apprehensive of the aerodynamic testing and became upset. With increased exposure to the equipment, the researchers were able to acquire data for all recruited subjects who participated in the study. Anecdotally, the experimenters found that calmly explaining the procedure to the child and then modeling the stimulus word hamper with a separate oral pressure tube and nasal olives was successful. The final limitation noted was controlling the rate of the subjects' repetitions of the stimulus item. The clinician modelled and explained instructions in an attempt to control for rate; however, some of the children had difficulty following the directions.

\section{Future Directions}

The researchers plan to recruit additional subjects in order to continue the current investigation and further examine the trends that were found in the data analysis. It is clear that statistical power was limited due to the small sample size, and the inclusion of additional subjects would allow more valid empirical scrutiny. Moreover, replication in other laboratories needs to be conducted to further investigate these findings and either support or refute the data generated from this preliminary investigation. 


\section{Appendix A}

Principal Investigator

Department

Protocol Number

Study Title

\section{Only Minimal Risk \\ Parental or Guardian Consent (Without HIPAA)}

Preschool Children and Those with Speech Sound Disorders

Co-Investigator(s)

Sponsor (if any)
Dennis Ruscello, Ph.D.

Communication Sciences and Disorders

1808241732

A Preliminary Investigation of Velopharyngeal Timing in Normally Developing

Taylor Snodgrass, B.S.

NA

\section{Contact Persons}

Click here to enter text.

In the event your child experiences any side effects or injury related to this research, you should contact Dennis Ruscello at (304)-293-2894 or Dennis.Ruscello@mail.wvu.edu. (After hours contact: Dennis Ruscello at (304)-692-9897 or Dennis.Ruscello@mail.wvu.edu or Taylor Snodgrass at (276) 224-3955 or tds0031@mix.wvu.edu. If you have any questions, concerns, or complaints about this research, you can contact Dennis Ruscello at (304)-293-2894 or Dennis.Ruscello@mail.wvu.edu. or Taylor Snodgrass at (276) 224-3955 or tds0031@mix.wvu.edu.

For information regarding your child's rights as a research subject, to discuss problems, concerns, or suggestions related to the research, to obtain information or offer input about the research, contact the Office of Research Integrity and Compliance (304) 293-7073.

In addition, if you would like to discuss problems, concerns, have suggestions related to research, or would like to offer input about the research, contact the Office of Research Integrity and Compliance at 304-2937073.

\section{Introduction}

Your child, has been asked to participate in this research study, which has been explained to you and your child by Dr. Dennis Ruscello or Ms. Taylor Snodgrass. This study is being conducted by Dennis Ruscello, Ph.D. and Taylor Snodgrass, B.S. in the Department of Communication Sciences and Disorders at West Virginia University with no funding or sponsorship. This research is being conducted in partial fulfillment of the requirements for a master's degree in Speech- Language Pathology in the Department of Communication Sciences and Disorders at West Virginia University, under the supervision of Dennis Ruscello, Ph.D.

\section{Purpose(s) of the Study}

The purpose of this study is to learn more about how the back of the throat opens and closes when a young child is talking. In order learn more, we are testing children with pronunciation problems and those who do not have pronunciation problems between the ages of 3 to 6 years. WVU expects to enroll approximately 30 subjects; a total of approximately 30 subjects at all sites are expected to participate in this study.

\section{Description of Procedures}


This study involves the assessment of speech in young children. We will first do some testing with your child to screen speech and hearing skills. This includes looking at the structures involved in speech (lips, teeth, tongue, and back of throat), an articulation test screening (looking at how your child pronounces certain speech sounds), and a hearing screening to determine if she/he has a hearing problem. As a parent, you will also be asked to complete a short questionnaire about how well you and others understand your child. If your child participates in the screening and qualifies, she/he will undergo testing to study the opening and closing of the back of the throat. Your child will say the test word, "hamper", several times while fitted with equipment to measure airflow in the mouth and nose. There will be a nasal airflow sensor via a nasal olive touching the nostrils, and an oral pressure sensing tube placed between the lips. Placement of the sensors will allow us to study how the back of the throat opens and closes during speech. This study will take about 45 minutes to an hour for your child to complete.

The study will be performed at the Allen Hall Speech and Hearing Center, which is located on 355 Oakland Street. The Center is on the Evansdale Campus of West Virginia University. Approximately 30 subjects are expected to participate in this study.

\section{Risks and Discomforts}

There are no known or expected risks to your child from participating in this study, except for the mild frustration associated with the screenings and airflow testing.

\section{Alternatives}

Your child does not have to participate in this study.

\section{Benefits}

Your child will receive direct benefit from this study in the form of a speech and hearing screening. The knowledge gained from this study may eventually benefit others.

\section{Financial Considerations}

Your child will receive a \$5 Chick-fil-A food card for being in the study.

\section{Confidentiality}

Any information about your child that is obtained as a result of their participation in this research will be kept as confidential as legally possible.

Your child's research records and test results, just like hospital records, may be subpoenaed by court order or may be inspected by the study sponsor or federal regulatory authorities without your additional consent.

Audiotapes or videotapes will be kept locked up and will be destroyed as soon as possible after the research is finished.

In any publications that result from this research, neither your child's name nor any information from which your child might be identified will be published without your consent.

\section{Voluntary Participation}

Refusal to participate or withdrawal will not affect your child's future care, [or your employee status at West Virginia University] and will involve no penalty to you.

\section{Signatures}

Upon signing this consent, you will receive a copy.

I willing consent to allow my child to participate in this research. 
Signature of Parent or Guardian

Printed Name

Date

Time

Signature of Investigator or Co-Investigator

Printed Name

Date

Time 


\section{References}

Anthony, J. L., Aghara, R. G., Dunkelberger, M. J., Anthony, T. I., Williams, J. M., \& Zhang, Z. (2011). What factors place children with speech sound disorders at risk for reading problems?. American Journal of Speech-Language Pathology, 20(2), 146-160.

Barlow, S. M., Poore, M. P., \& Chu S. Y. (2011). Biodynamics of speech and orofacial movement. In A. Lowit \& R. J. Kent, Assessment of motor speech disorders (193-229). San Diego, CA: Plural Publishing.

Bunton, K., Hoit, J. D., \& Gallagher, K. (2011). A simple technique for determining velopharyngeal status during speech production. Seminars in Speech and Language, 32(1), 69-80.

Bunton, K. \& Hoit, J. (2018). Development of velopharyngeal closure for vocalization during the first 2 years of life. Journal of Speech, Language, and Hearing Research, 61, 549-560.

Bunton, K. (2018). Update on velopharyngeal closure in young children. Perspectives of the ASHA Special Interest Group, SIG 5(3;1), 4-12.

Case, J., \& Grigos, M. I. (2016). Articulatory control in childhood apraxia of speech in a novel word-learning task. Journal of Speech, Language, and Hearing Research, 59(6), 12531268.

Casper, J. (1985). Disorders of speech and voice. Pediatric annals, 14(3), 220-229.

Cohen, J. (1977). Statistical power analysis for behavioral sciences (revised ed.). New York: Academic Press.

Cohen, J. (1988). Statistical power analysis for the behavioral sciences (2nd ed.). Hillsdale, N.J.: L. Erlbaum Associates.

Dodd, B., Hua, Z., Crosbie, S., Holm, A., \& Ozanne, A. (2009). Diagnostic Evaluation of Articulation and Phonology-US Edition (DEAP). San Antonio, TX: Pearson.

Eshghi, M., Vallino, L. D., Baylis, A. L., Preisser, J. S., \& Zajac, D. J. (2017). Velopharyngeal status of stop consonants and vowels produced by young children with and without repaired cleft palate at 12,14, and 18 months of age: A preliminary analysis. Journal of Speech, Language, and Hearing Research, 60(6), 1467-1476.

Fluharty, N. B. (2001). Fluharty-2: Fluharty Preschool Speech and Language Screening test. Pro-ed.

George, D., \& Mallery, P. (1999). SPSS® for Windows ${ }^{\circledR}$ step by step: A simple guide and reference. Allyn \& Bacon.

Green, J. R., Moore, C. A., \& Reilly, K. J. (2002). The sequential development of jaw and lip control for speech. Journal of Speech, Language, and Hearing Research, 45(1), 66-79. 
Grigos, M. I., Hayden, D., \& Eigen, J. (2010). Perceptual and articulatory changes in speech production following PROMPT treatment. Journal of Medical Speech-Language Pathology, 18, 46-53.

Grigos, M. I., Moss, A., \& Lu, Y. (2015). Oral articulatory control in childhood apraxia of speech. Journal of Speech, Language, and Hearing Research, 58, 1103-1118.

Kent, R. D. (2017). Normal aspects of articulation. In J. E. Bernthal, N. W. Bankson, \& P. Flipsen, Articulation and phonological disorders (7-48). Boston, MA: Pearson.

Kent, R. D. (2000). Research on speech motor control and its disorders: a review and prospective. Journal of Communication Disorders 33, 391-428.

Leeper, H. A., Tissington, M. L., \& Munhall, K. G. (1998). Temporal characteristics of velopharyngeal function in children. The Cleft palate-craniofacial journal, 35(3), 215221.

MacNeilage, P. F. \& Davis, B. L. (1990a). Acquisition of speech production: Frames, then content. In M. Jeannerod (Ed.), Attention and performance XIII: Motor representation and control (453-476). Hillsdale, NJ: Lawrence Erlbaum.

MacNeilage, P. F. \& Davis, B. L. (1990b). Acquisition of speech production: The achievement of segmental independence. In W. J. Hardcastle \& A. Marchal (Eds.), Speech Production and Modeling (55-68). Dordrecht: Kluwer Academic.

McLeod, S., Harrison, L. J., \& McCormack, J. (2012). The intelligibility in context scale: validity and reliability of a subjective rating measure. Journal of Speech, Language, and Hearing Research, 55, 648-656.

Moss, A., \& Grigos, M. I. (2012). Interarticulatory coordination of the lips and jaw in childhood apraxia of speech. Journal of Medical Speech-Language Pathology, 20, 127-132.

Nip, I. S. B., Green, J.R., \& Marx, D. B. (2009). Early speech motor development: Cognitive and linguistic considerations. Journal of Communication Disorders, 42, 286-298.

Perkell, J. S. (2013). Five decades of research in speech motor control: What have we learned, and where should we go from here?. Journal of Speech, Language, and Hearing Research, 56(6), S1857-S1874.

Peterson-Falzone, S., Hardin-Jones, M., \& Karnell, M. (2010). Cleft palate speech (4th ed. / ed.). St. Louis, Mo.: Mosby/Elsevier.

Ruscello, D. M. \& Vallino-Napoli, L. The application of motor learning concepts to the treatment of children with compensatory speech sound errors. Perspectives, SIG 5, Speech Science and Orofacial Disorders, 24, 39-47 (2014).

Rvachew, S., \& Brosseau-Lapré, F. (2016). Developmental phonological disorders: Foundations of clinical practice. Plural Publishing. 
Shriberg, L. D. \& Kwiatkowski, J. (1994). Developmental phonological disorders I: a clinical profile. Journal of Speech, Language, and Hearing Research, 37, 1100-1126.

Shriberg, L. D., Lohmeier, H. L., Strand, E. A., \& Jakielski, K. J. (2012). Encoding, memory and transcoding deficits in childhood apraxia of speech. Clinical Linguistics and Phonetics, 26, 445-482.

St. Louis, K. O., \& Ruscello, D. M. (2000). Oral speech mechanism screening examinationThird edition (OSMSE-3). The Psychological Corporation, San Antonio, TX.

Terband, H., Maassen, B., Van Lieshout, P., \& Nijland, L. (2011). Stability and composition of functional synergies for speech movements in children with developmental speech disorders. Journal of Communication Disorders, 44(1), 59-74.

Thom, S., M.S., Hoit, J., Ph.D., Hixon, T., Ph.D., \& Smith, A., Ph.D. (2006). Velopharyngeal function during vocalization in infants. The Cleft Palate-Craniofacial Journal, 43(5), 539-546. doi:10.1597/05-113

Vick, J. C., Campbell, T. F., Shriberg, L. D., Green, J. R., Truemper, K., Rusiewicz, H. L., \& Moore, C. A. (2014). Data-driven subclassification of speech sound disorders in preschool children. Journal of Speech, Language, and Hearing Research, 57(6), 20332050.

Walsh, B., \& Smith, A. (2002). Articulatory movements in adolescents: Evidence for protracted development of speech motor control processes. Journal of Speech, Language, and Hearing Research, 45(6), 1119-1133.

Warren, D. W., \& DuBois, A. B. (1964). A pressure-flow technique for measuring velopharyngeal orifice area during continuous speech. Cleft palate Journal, 1(1), 52-71.

Warren, S. F., Yoder, P. J., Gazdag, G. E., Kim, K., \& Jones, H. A. (1993). Facilitating prelinguistic communication skills in young children with developmental delay. Journal of Speech, Language, and Hearing Research, 36(1), 83-97.

Weisstein, E. W. (2004). Bonferroni correction.

Zajac, D.J., Vallino-Napoli, L. (2017). Evaluation and management of individuals with cleft lip and palate: A developmental perspective. San Diego: Plural Publishing.

Zajac, D. J., \& Hackett, A. M. (2002). Temporal characteristics of aerodynamic segments in the speech of children and adults. The Cleft palate-craniofacial journal, 39(4), 432-438.

Zajac, D. J. (2000). Pressure-flow characteristics of $/ \mathrm{m} / \mathrm{and} / \mathrm{p} /$ production in speakers without cleft palate: Developmental findings. The Cleft palate-craniofacial journal, 37(5), 468-477. 